\title{
Podem as Redes Metalo- Orgânicas Ajudar no Diagnóstico de Vírus?
}

Flávio Figueira*

Filipe A. Almeida Paz*

\author{
Can Metal-Organic Networks Help in Virus \\ Diagnosis? Laboratory diagnosis of pathologies \\ caused by virus plays a critical role in the \\ outbreak response efforts and in establishing \\ safe and rapid testing strategies. The detection \\ of pathogenic viruses using commercial \\ solutions often requires specific tools and \\ laborious laboratory procedures, rendering \\ the detection of virus infections complex and \\ time-consuming. The widely known intrinsic \\ properties of Metal-Organic Frameworks \\ (MOFs) embody them with great potential to \\ overcome some of the challenges inherent to \\ virus detection. These are now widely used \\ in functional device components capable \\ of performing uninterrupted detection of \\ molecular targets in real time. In this short \\ review, studies on MOFs used as sensors for \\ pathogenic viruses are discussed, emphasizing \\ the structural and physical properties that give \\ them an edging advantage when building new \\ sensors for infectious agents.
}

O diagnóstico laboratorial de patologias causadas por vírus desempenha um papel crítico nos esforços de resposta a surtos e na definição de estratégias de testagem rápidas e seguras. A deteção de vírus patogénicos tipicamente requer ferramentas específicas e procedimentos laboratoriais morosos, tornando a deteção de infeções virais complexa e demorada. As propriedades intrínsecas e amplamente conhecidas das Redes MetaloOrgânicas (MOFs) têm o potencial de superar alguns dos desafios inerentes à deteção de vírus. Estes compostos são, hoje em dia, amplamente utilizados como componentes de dispositivos funcionais capazes de realizar uma deteção ininterrupta de alvos moleculares em tempo real. Nesta revisão são discutidos estudos em MOFs usados como sensores de vírus patogénicos, enfatizando algumas propriedades estruturais e físico-químicas que lhes conferem vantagem face ao desenvolvimento de novos sensores para estes agentes infeciosos.

\begin{abstract}
Introdução
Os vírus estão na génese de um elevado número de doenças tais como a varicela, a g'ripe, a síndrome da imunodeficiência adquirida (HIV), a síndrome respiratória aguda grave (SARS), o ébola, entre outras [1-3]. O seu pequeno tamanho (normalmente de 20 a $900 \mathrm{~nm}$ ) e a sua simplicidade estrutural permitem-Ihes uma rápida adaptação a novos ambientes através de evoluções espontâneas que podem ocorrer através de mutações genéticas diretas, substituição genética ou recombinação [4,5]. Estas características, aliadas ao crescente número de descobertas de novos vírus (muitos com composições genéticas semelhantes) e infeções virais, não só suplantam as tentativas de desenvolver estratégias sustentáveis de controlo, como levantam também questões acerca da adequação e validade das técnicas de diagnóstico atualmente disponíveis [6].
\end{abstract}

Uma realidade incontornável é o ressurgimento ou o aparecimento de novas infeções virais. Tal é sustentado por graves pandemias e epidemias ocorridas em todo o mundo nos últimos anos. Destas ocorrências, a mais significativa centra-se no surto mundial de SARS-CoV-2 que provoca a COVID-19, bem presente no momento em que esta pequena revisão foi escrita. Com pouco mais de 125 milhões de casos e mais de 2,7 milhões de vítimas em todo o mundo a 24 de março de 2021 (início da primavera no hemisfério norte), esta pandemia parou as principais economias mundiais obrigando, em muitos casos, a um isolamento intermitente dos cidadãos [7].

Um estudo recente monitorizou a progressão do ébola usando um simulador de epidemia padronizado para uma população de 10 milhões de indivíduos e uma taxa de reprodução básica de 2,0 [8]. Este estudo 
estimou que a disseminação viral de $80 \%$ cai para quase $0 \%$ se $60 \%$ dos pacientes com ébola forem diagnosticados no primeiro dia com sintomas, em vez da média normal de cinco dias após os primeiros sintomas. Este estudo demonstra que um rápido diagnóstico de uma infeção viral recorrendo a testes rápidos permite uma forte redução da janela de transmissão. Este tipo de testes é particularmente vantajoso em situações em que os portadores são assintomáticos [9]. A importância de métodos rápidos, simples, sensíveis e precisos para a deteção de agentes virais no momento e local do atendimento ao paciente é, agora mais do que nunca, uma necessidade (imperativa) $[9,10]$.

A maioria das novas tecnologias capazes de diagnosticar vírus centram-se no desenvolvimento de biossensores [11], que são dispositivos analíticos compostos por um elemento de reconhecimento biológico para a deteção de um analito-alvo e um transdutor - o próprio sensor - que converte os sinais num parâmetro mensurável. 0 elemento biológico pode ser uma biomolécula, uma enzima, anticorpos ou até mesmo um organismo. 0 transdutor, por seu lado, pode ser ótico, quimiorresistivo, eletroquímico ou piezoelétrico [12-19]. Os biossensores possuem vantagens imediatas, tais como resultados rápidos e seletividade; nos últimos anos as suas sensibilidade e especificidade evoluíram de forma significativa criando novas estratégias para a modificação de superfície tendo em vista a amplificação de sinal na deteção de diferentes biomoléculas [20]. Vários nanomateriais com diferentes morfologias baseados em estruturas de carbono, nanopartículas de ouro e Redes Metalo-Orgânicas (MOFs) têm vindo a ser modificados principalmente através de métodos não covalentes para aplicações biomédicas devido às suas características elétricas, óticas e mecânicas [21-23].

\section{MOFs na deteção de vírus}

Os MOFs possuem diversas propriedades que os tornam candidatos perfeitos no reconhecimento molecular e em aplicações específicas como é o caso dos biossensores. Destacam-se a elevada porosidade e área superficial, cristalinidade, composição química ajustável (podendo ser modificada por funcionalização pós-sintética) e baixa toxicidade (dependendo da combinação de ligandos e metais, e da sua biodisponibilidade) [24-27].

A incorporação de biomoléculas em MOFs é uma vantagem que não se restringe apenas a biossensores, sendo transversal a outros materiais biomiméticos como é o caso de biocatalisadores [28-30]. A elevada porosidade dos MOFs possibilita o seu uso na incorporação de biomoléculas (protegendo-as do ambiente químico externo), permitindo também que sejam usados como suportes físicos. No caso particular dos biossensores, podem ser suportadas de forma estável e duradoura

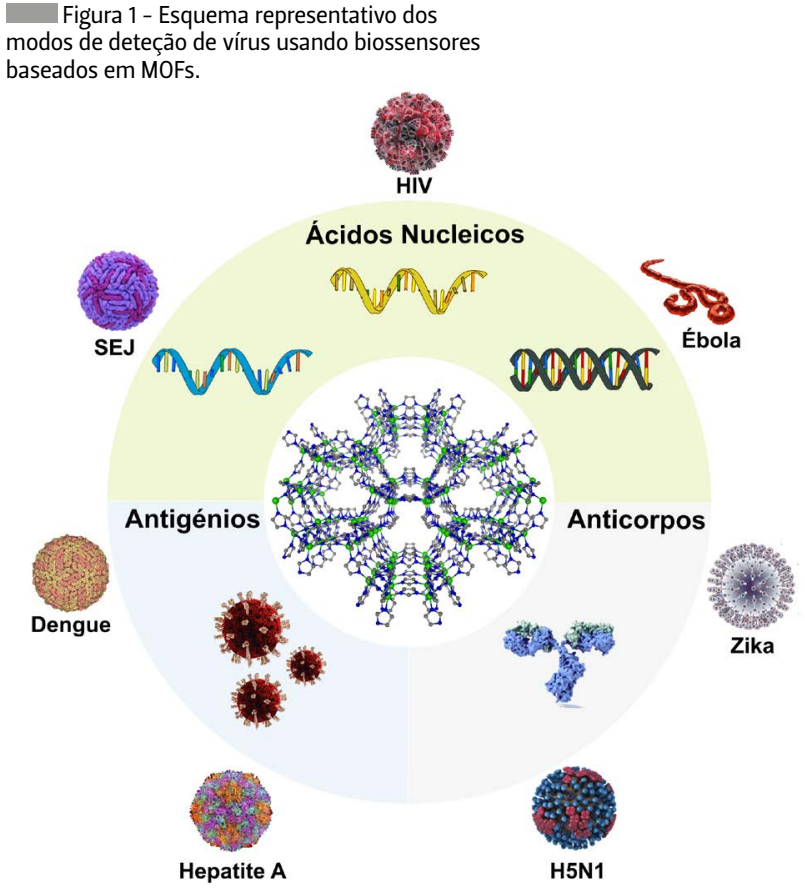

biomoléculas sensíveis à temperatura ou luz, reduzindo a necessidade de refrigeração e manipulações mais complexas [31]. Um ajuste criterioso das propriedades de absorção e emissão dos MOFs (modificando os ligandos e os metais que compõem estas estruturas) pode ainda promover o reconhecimento molecular para determinadas células e biomoléculas [32-34]. Nos últimos anos foram desenvolvidas diferentes aplicações médicas e clínicas para plataformas de biossensores baseados em MOFs envolvendo: a) diagnóstico rápido e tratamento de doenças como o cancro ou a diabetes; $b$ ) deteção de agentes patogénicos; c) dosagem de drogas e seus metabolitos; d) descoberta de novos fármacos; e) avaliação e medição de analitos em amostras biológicas e f) deteção precoce de doenças recorrendo a testes rápidos [35-38].

0 presente artigo resume as plataformas mais comuns para a deteção de vírus com base em MOFs recorrendo a ácidos nucleicos e deteção imunológica (anticorpos e antigénios) (Figura 1). Os mecanismos de deteção dos ácidos nucleicos virais são compilados de acordo com os MOFs que apresentam melhores propriedades de deteção para cada vírus. Finalmente discutem-se alguns desafios e direções futuras para a deteção de vírus usando MOFs.

\section{Deteção de ácidos nucleicos virais}

A deteção de vírus por reconhecimento de ácidos nucleicos consiste em introduzir nos poros do MOF (através de interações eletrostáticas) uma cadeia simples (ou dupla) de DNA complementar ao material genético viral, marcada (por ligações covalentes ou 
interações intermoleculares fortes) com uma sonda fluorescente que interage com a rede porosa promovendo uma diminuição da fluorescência. Este tipo de deteção requer que a amostra viral sofra um pré-tratamento para que o seu material genético seja exposto e a sua correspondente hibridização com a sonda viral que interage com o MOF seja possível. Uma vez que as interações entre as cadeias de DNA ou RNA complementares são mais fortes do que as existentes entre o poro do MOF e a cadeia sonda no seu interior, a libertação desta da superfície do MOF promove um aumento da fluorescência. Este método de deteção é o mais utilizado para várias famílias de vírus. É importante salientar que o desempenho dos MOFs enquanto plataformas de deteção de vírus pode ser ajustado por alteração química dos grupos funcionais dos ligandos ou por substituição dos centros metálicos (Figura 2). Para este fim, foram desenvolvidos diferentes ligandos para preparar os MOFs discutidos no presente trabalho (Esquema 1).

Num artigo de 2014 publicado na revista da Sociedade Portuguesa de Química (SPQ), oito métodos de síntese são delineados, descritos e diferenciados [39]. Entre estes salientam-se os métodos solvotérmicos e de micro-ondas como sendo os mais amplamente utilizados na preparação de MOFs. Os métodos solvotérmicos normalmente recorrem à utilização de vasos fechados sob pressão autogerada a temperaturas acima do ponto de ebulição do(s) solvente(s) selecionado(s) (quando o solvente é água o método designa-se por síntese hidrotérmica) [40]. A temperatura e a pressão da reação são os principais parâmetros a serem controlados, sendo que este método geralmente requer longos tempos de reação (dias a semanas), equipamentos volumosos e grande consumo de energia. Por outro lado, a preparação de MOFs usando aquecimento assistido por micro-ondas envolve frequentemente tempos de reação mais curtos, um maior controle do tamanho das partículas e uma elevada eficiência energética $[41,42]$.

A grande maioria dos MOFs desenvolvidos para a deteção de vírus foram sintetizados através de métodos solvotérmicos combinando os ligandos apresentados no Esquema 1 com catiões de metais de transição ou lantanídeos $\left(\mathrm{Cu}^{2+}, \mathrm{Zn}^{2+}, \mathrm{Fe}^{3+}, \mathrm{Cr}^{3+}, \mathrm{La}^{3+}\right.$ e Dy $\left.{ }^{3+}\right)$. $\mathrm{Na}$ Figura 2 são apresentadas as estruturas e respetivas fórmulas moleculares dos MOFs descritos nesta revisão.

Os tempos de resposta e os limites de deteção (LD) estão intrinsecamente relacionados com a forma como as sondas interagem com os MOFs. As estruturas mais estudadas tiram, dessa forma, proveito de interações eletrostáticas, sendo que os MOFs com superfícies carregadas positivamente são os mais eficazes para tirarem partido das cargas negativas presentes nas

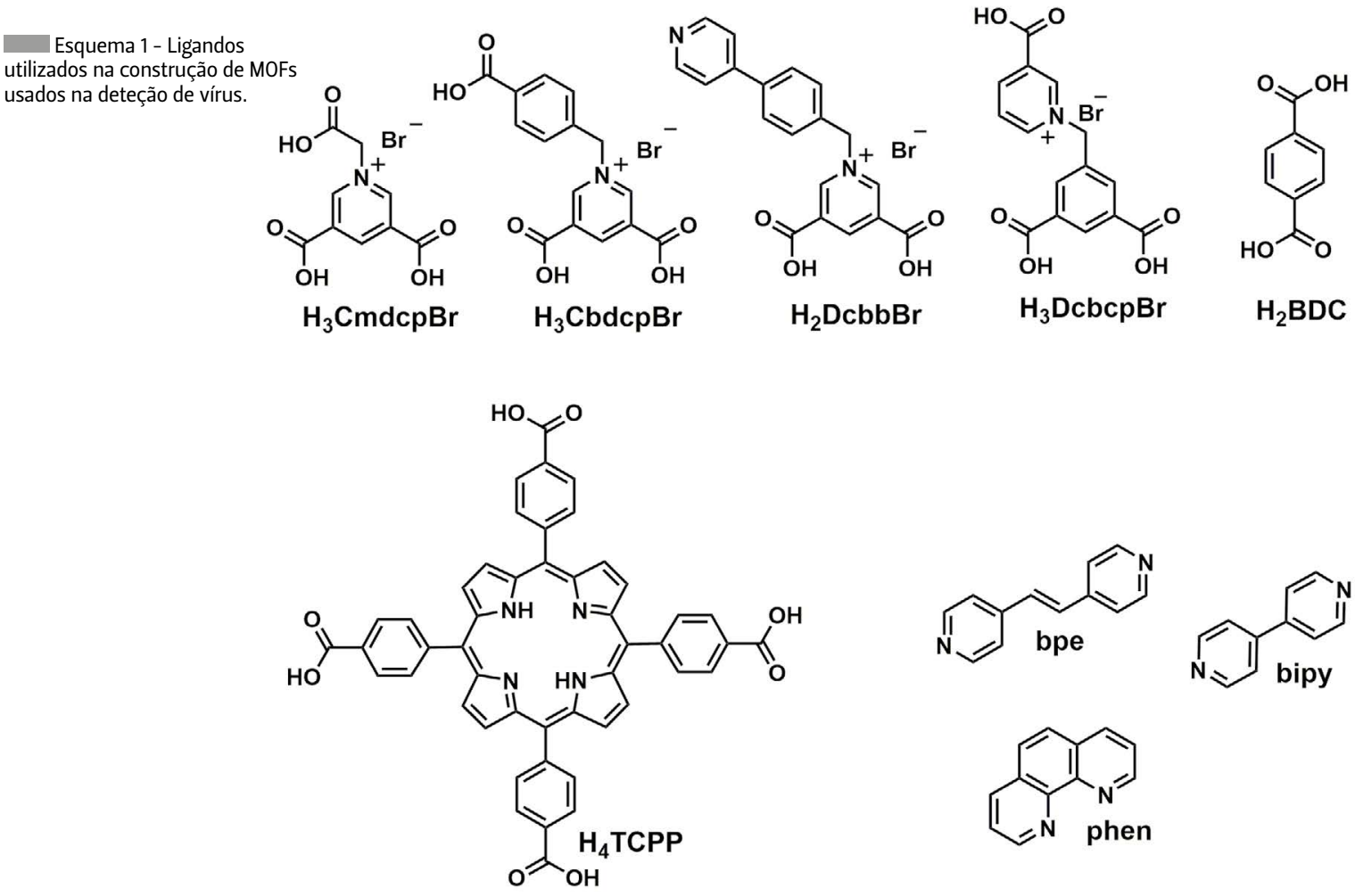

bpe: 4,4'-vinilenodipiridina; bipy: 4,4'-bipiridina; $\mathrm{H}_{2} \mathrm{BDC}$ : ácido tereftálico; $\mathrm{H}_{2} \mathrm{DcbbBr}$ : brometo de 1-(3,5-dicarboxibenzilo)-4,4'-bipiridina; $\mathrm{H}_{3} \mathrm{CmdcpBr}$ : brometo de 3,5-dicarboxilo- $\mathrm{N}$-carboximetilpiridínio; $\mathrm{H}_{3} \mathrm{CbdcpBr}$ : brometo de 1-(3,5-dicarboxilo)-4-(carboxibenzilo)piridínio; $\mathrm{H}_{3} \mathrm{Dcb} c \mathrm{c} B \mathrm{Br}$ : brometo de 1-(3,5-dicarboxilo)-3-(carboxibenzilo)piridínio; $\mathrm{H}_{4}$ TCPP: 5,10,15,20-tetraquis(4-carboxifenil)porfirina; phen: 1,10-fenantrolina. 


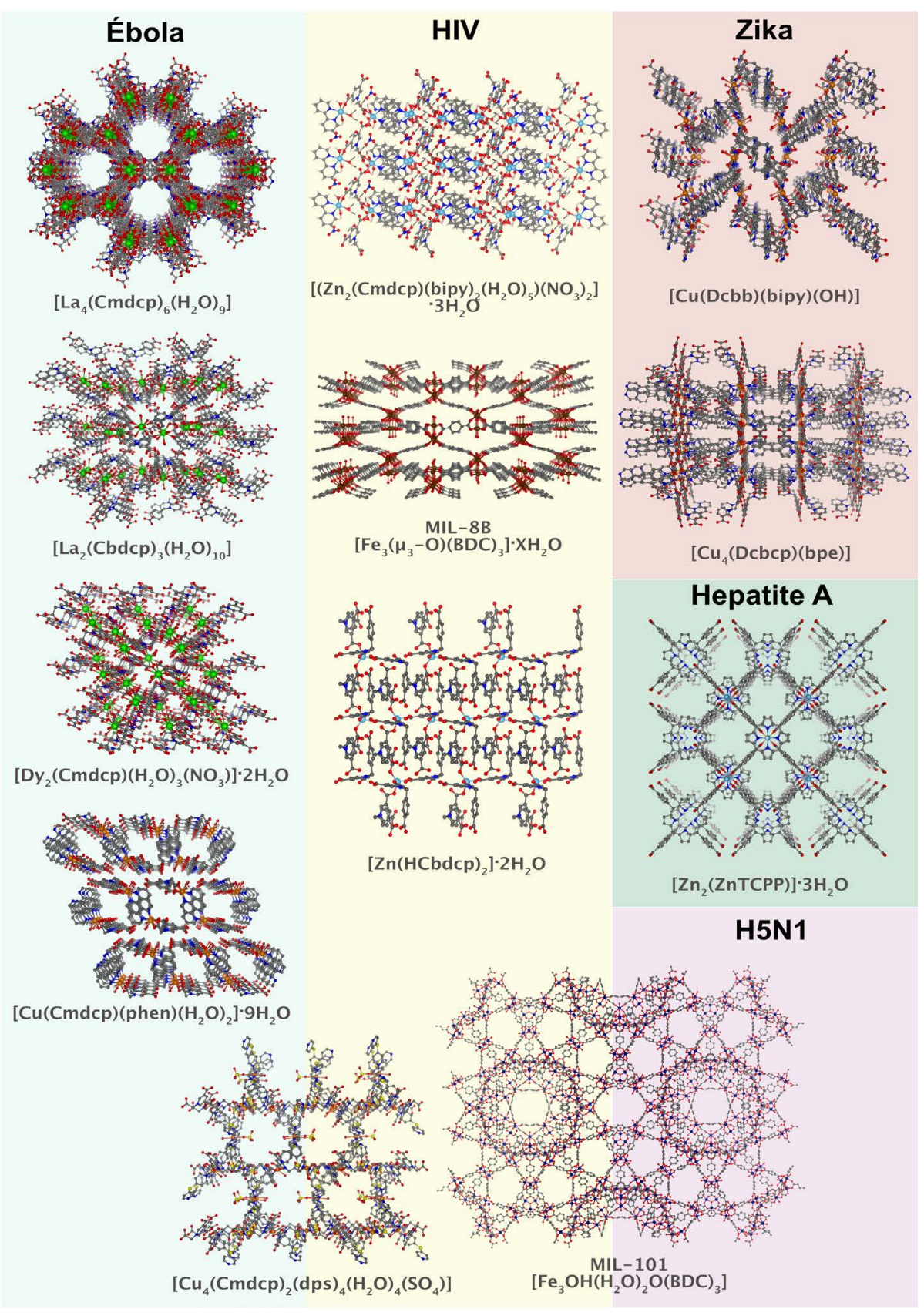

Figura 2 - MOFs usados como biossensores de vírus.

cadeias das sondas de DNA viral. Fazendo uso desta abordagem, o MOF $\left[\right.$ Dy $\left.2(\mathrm{Cmdcp})\left(\mathrm{H}_{2} \mathrm{O}\right)_{3}\left(\mathrm{NO}_{3}\right) \cdot 2 \mathrm{H}_{2} \mathrm{O}\right]$ é capaz de reconhecer uma porção do RNA viral do vírus ébola com um LD de apenas 160 pM em cerca de 120 minutos (Figura 3) [43]. Os MOFs baseados em lantanídeos, tais como $\left[\mathrm{La}_{4}(\mathrm{Cmdcp})_{6}\left(\mathrm{H}_{2} \mathrm{O}\right)_{9}\right]$ e $\left[\mathrm{La}_{2}(\mathrm{Cbdcp})_{3}\left(\mathrm{H}_{2} \mathrm{O}\right)_{10}\right]$, mostraram uma eficiência superior na deteção do mesmo vírus, baixando o tempo de deteção para apenas 40 minutos com um LD de 67 pM [44].

Um uso mais alargado desta estratégia (incorporação de um fragmento de DNA viral em MOFs) permitiu a deteção de outros vírus, assim como de vários em simultâneo [45-51]. Um exemplo deste modo de deteção é demonstrado com o MOF $\left[\mathrm{Cu}(\mathrm{Cmdcp})(\text { phen })\left(\mathrm{H}_{2} \mathrm{O}\right)\right]_{2} \cdot 9 \mathrm{H}_{2} \mathrm{O}$, capaz de detetar em simultâneo microRNA (miRNA) e sequências de RNA conservadas do vírus ébola com limites de deteção de 206 pM e 60 pM, respetivamente (Figura 4) [45]. Este MOF possui tempos de deteção mais curtos que os materiais anteriormente descritos, precisando de apenas 12,5 minutos para detetar o miRNA e 3 minutos para a sequência de RNA viral.

Com o intuito de melhorar estes resultados, foram usados ligandos aromáticos auxiliares com o MOF $\left[\mathrm{Cu}_{4}(\mathrm{Cmdcp})_{2}(\mathrm{dps})_{4}\left(\mathrm{H}_{2} \mathrm{O}\right)_{4}\left(\mathrm{SO}_{4}\right)\right]$ de forma a aumentar 
as interações п-п da rede e, dessa forma, modular a interação com a sonda de DNA. Este composto foi utilizado para detetar, em simultâneo, os vírus ébola e HIV com baixos limites de deteção (73 pM para o ébola e 196 pM para o HIV) e com tempos de resposta de 30 e 90 minutos, respetivamente [46]. Este estudo originou resultados menos surpreendentes que os observados anteriormente. No entanto, o trabalho demonstra a grande importância do tipo e da natureza de interações entre sondas de DNA, e entre a rede porosa dos MOFs e as sondas de DNA no sentido de preparar materiais com elevada afinidade para os vírus em estudo.

Utilizando um mecanismo de deteção ligeiramente diferente do apresentado anteriormente, MOFs mais convencionais (e comerciais) como é o caso MIL-101 foram usados como plataforma de adsorção, em simultâneo, de uma cadeia de DNA e de um fluoróforo [52]. Neste estudo a sonda de DNA não foi ligada covalentemente com o fluoróforo: os autores adotaram uma estratégia onde ambos são adsorvidos no MOF. Esta combinação foi utilizada no sentido de melhorar a razão sinal/ruído em quase oito vezes na deteção do HIV-1, com um limite de deteção de cerca de 73 pM (Figura 5). A mesma equipa de investigadores usou mais tarde o mesmo MOF para desenvolver uma plataforma para a deteção do HIV-1 com uma sonda de DNA ligada covalentemente ao fluoróforo. 0 material resultante originou, infelizmente, um biossensor com um limite de deteção bem acima dos registados anteriormente (0,2 nM) [53]. A utilização de um MOF nanométrico (com morfologia do tipo agulha) baseado no mesmo ligando mas com uma estrutura distinta (MIL-88B) originou um biossensor capaz de detetar o mesmo vírus com um limite de deteção bastante meIhorado (10 pM) e com um tempo de deteção de apenas 4 minutos [54]. Estes resultados demonstram que não é só a porosidade que orienta as interações a um nível molecular na deteção de cadeias virais: a morfologia e o tamanho de partícula do MOF desempenham também um papel relevante. Salienta-se, no entanto, que até à data apenas uma pequena parte dos trabalhos investigaram o efeito da morfologia dos materiais na preparação e eficiência de biossensores para vírus.
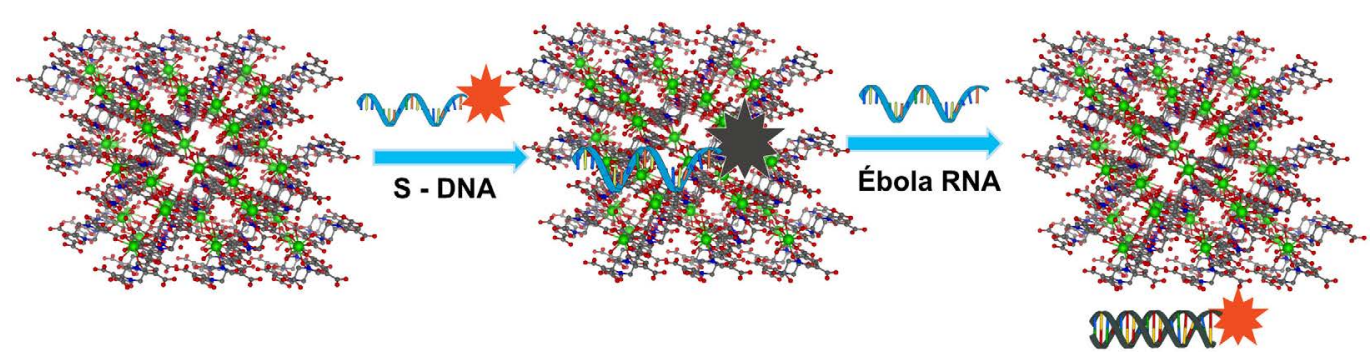

Figura 3 - Mecanismo de deteção para o RNA do vírus ébola usando o MOF $\left[\mathrm{Dy}_{2}(\mathrm{Cmdcp})\right.$ $\left.\left(\mathrm{H}_{2} \mathrm{O}\right)_{3}\left(\mathrm{NO}_{3}\right)\right] \cdot 2 \mathrm{H}_{2} \mathrm{O}$ com uma sonda de DNA (S-DNA) recíproca ao RNA do ébola. Reproduzido com permissão a partir da referência [43].
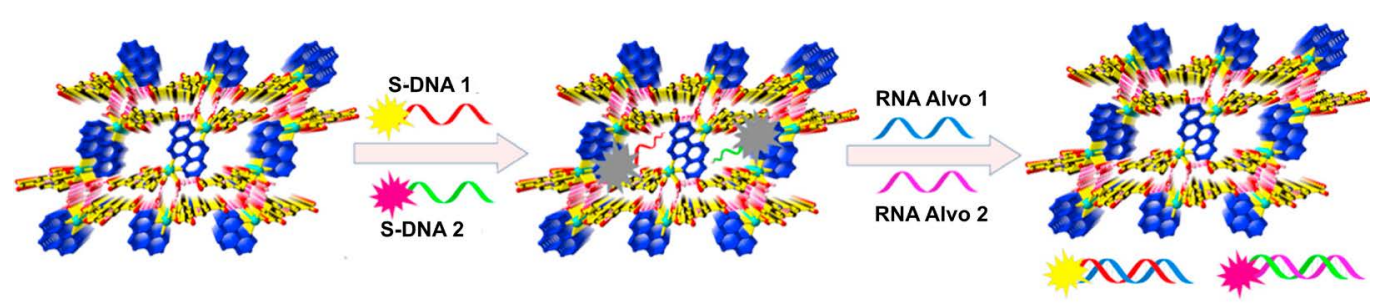

Figura 4 - Mecanismo para a deteção sincronizada de sequências de RNA do vírus ébola (RNA alvo 1 miRNA, e RNA alvo 2 - RNA viral) com um biossensor fluorescente composto pelo MOF $[\mathrm{Cu}(\mathrm{Cmdcp})$ (phen) $\left.\left(\mathrm{H}_{2} \mathrm{O}\right)\right] \cdot 4,5 \mathrm{H}_{2} \mathrm{O}$. Reproduzido com permissão a partir da referência [45].

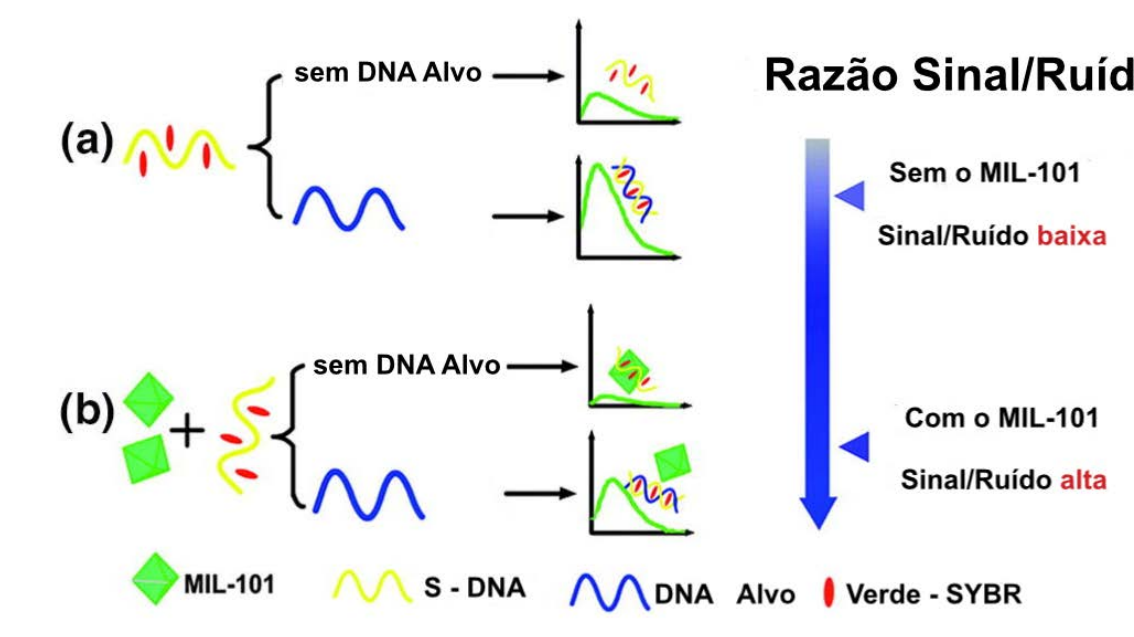

Figura 5 - Mecanismo para aumentar a razão sinal/ruído (a) sem e (b) com MIL-101. Reproduzido com permissão a partir da referência [52]. 


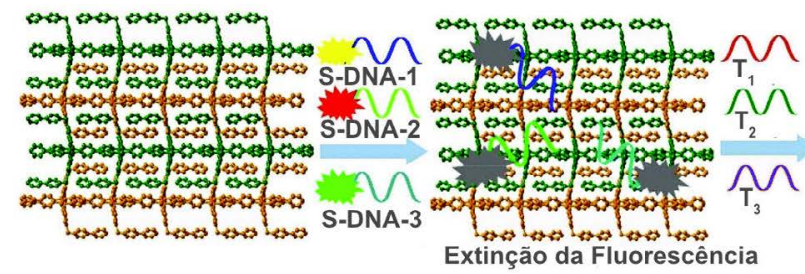

Extinção da Fluorescência

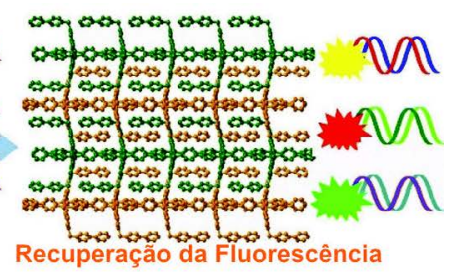

Figura 6 - Mecanismo proposto para a deteção de fluorescência sincronizada pelo material lamelar $[\mathrm{Cu}(\mathrm{Dcbb})(\mathrm{bipy})(\mathrm{OH})]$. Reproduzido com permissão a partir da referência [55].
Até agora foram poucos os materiais desenvolvidos capazes de diagnosticar o vírus Zika, principalmente porque a sua deteção é muito difícil durante o período de incubação $[55,56]$. Na tentativa de conseguir um diagnóstico precoce para esta infeção viral, foi construída uma plataforma para a deteção de RNA de diferentes vírus sem reação cruzada introduzindo em simultâneo três sondas de DNA distintas num MOF lamelar: [Cu(Dcbb)(bipy)(OH)] (Figura 6) [55]. Cada uma destas sondas é capaz de interagir com três regiões diferentes do RNA do vírus Zika (T1, T2 e T3), tendo sido marcadas com fluoróforos distintos FAM (S-DNA-1, carboxifluoresceína), ROX (S-DNA-2, rodamina X) e Cy5 (S-DNA-3, cianina 5).

0 mecanismo de deteção é em tudo semelhante aos anteriores, havendo uma recuperação da fluorescência na presença do RNA alvo, com concentrações de $25 \mathrm{nM}$ em apenas 12, 2,3 e 3 minutos para as sondas marcadas com FAM, ROX e Cy5, respetivamente. Os limites de deteção obtidos para cada sonda foram de 0,56 nM (sonda FAM), 0,16nM (sonda ROX) e 0,19 nM (sonda (y5). É interessante notar que não é observada nenhuma reação cruzada: se apenas o T1 for introduzido na solução com o sistema com as três sondas a emissão recuperada é observada apenas para a sonda correspondente (Figura 6). Esta pode ser uma estratégia simples e eficaz para detetar vírus semelhantes com elevada especificidade.

\section{Deteção imunológica}

Embora a deteção de cadeias de ácidos nucleicos seja o Santo Graal para o diagnóstico de diferentes vírus, sofre bastante com os resultados de "falsos negativos", risco de contaminação e elevado custo. 0 método de deteção imunológica baseado na ligação específica entre antigénios e anticorpos tem como vantagens ser uma operação simples, com tempos de deteção curtos, sendo adequado para deteções no local. A deteção imunológica de vírus baseada em MOFs pode ser dividida em: i) deteção baseada em antigénio, e ii) deteção baseada em anticorpos. Os testes que detetam antigénios, proteínas específicas presentes na superfície do vírus, podem rapidamente identificar pessoas que estão no pico da infeção quando os níveis do vírus estão altos. Estes testes ajudam a manter o controle sobre epidemias e pandemias visto poderem ser implementados em grande escala e sinalizar aqueles que estão em maior risco de espalhar a doença.
Foram recentemente descritas plataformas baseadas em MOFs capazes de detetar partículas virais inteiras (viáveis ou não). Estes sistemas inovadores são baseados na modificação da superfície de um MOF com um polímero depositado por uma técnica denominada "impressão molecular". Este método cria uma superfície de reconhecimento inteligente com cavidades específicas para a forma do vírus alvo (reconhecimento superficial do vírus, tanto pela forma como pelos grupos químicos presentes na sua superfície). Isto possibilita uma simples implementação e integração em clínicas porque elimina a necessidade de processamento de amostras para extrair o DNA ou RNA viral. Esta tecnologia foi desenvolvida por dois grupos de investigação em separado usando o MOF MIL-101 modificado com cromo $[57,58]$. Os materiais foram capazes de diagnosticar o vírus da encefalite japonesa (VEJ) e o vírus da hepatite A, sendo extremamente sensíveis com limites de deteção na ordem dos 13 pM e 0,1 pM, respetivamente.

A deteção de anticorpos produzidos pelo sistema imunitário aquando de uma infeção viral usando MOFs foi desenvolvida para o diagnóstico do vírus da gripe H5N1 [59]. Para este fim, o MOF [ $\mathrm{H}_{2}$ dtoaCu] (onde dtoa corresponde a ditiooxamida) foi investigado mostrando um limite de deteção na ordem dos 1,6 nM. Até à data os materiais foram utilizados como plataformas para extinguir a fluorescência de sondas que são posteriormente libertadas recuperando a sua fluorescência. No entanto, esta rede metalo-orgânica responde à presença de anticorpos do H5N1, não apresentando qualquer fluorescência (Figura 7). A plataforma de deteção é composta pelo MOF, por DNA covalentemente ligado a um fluoróforo e um antigénio do H5N1. Na ausência do anticorpo H5N1, a sonda fluorescente é hidrolisada no terminal 3' pela exonuclease I (Exol), provocando a libertação do fluoróforo com a consequente recuperação da fluorescência. Por sua vez, quando o anticorpo H5N1 está presente, ele combina-se com o antigénio H5N1 na extremidade da sonda fluorescente protegendo a hidrólise pela Exol, o que implica que a fluorescência não é recuperada (Figura 7).

\section{Conclusão e perspetivas futuras}

A deteção precoce de doenças com potencial epidémico é um fator-chave na manutenção da saúde pública 


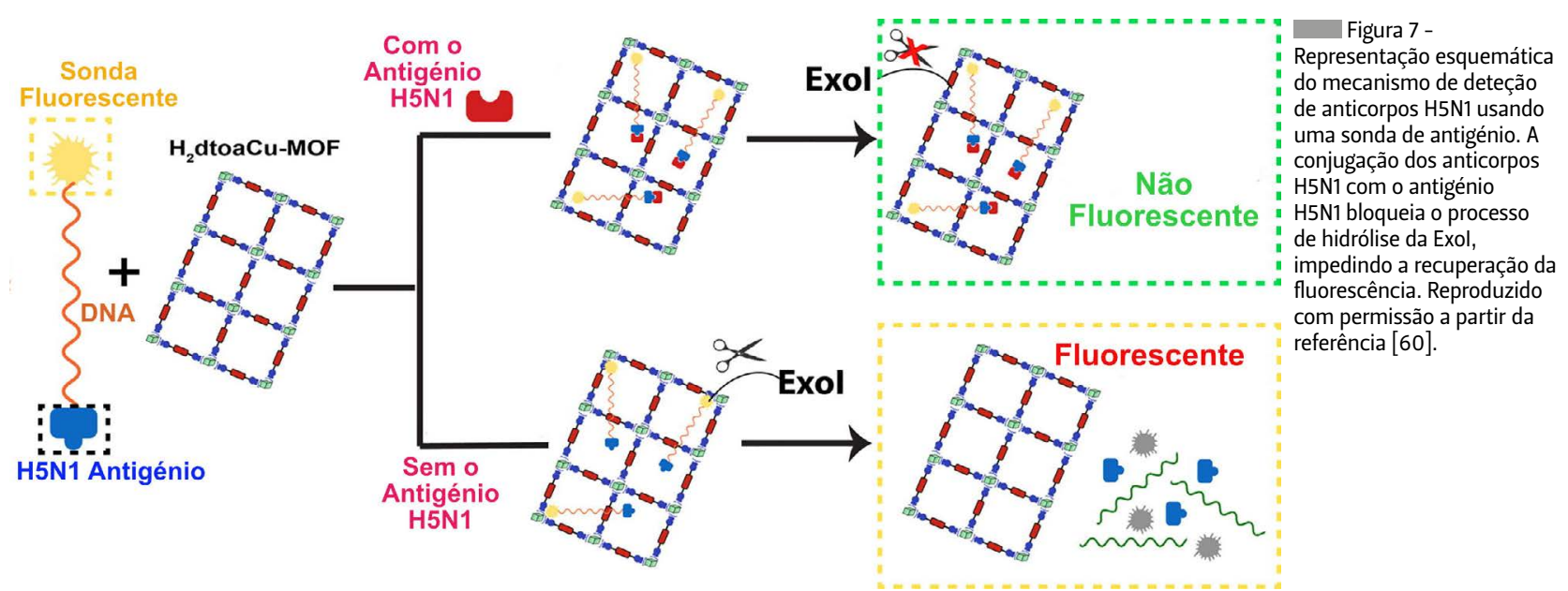

e na prevenção da disseminação de doenças virais. Atualmente, as técnicas mais difundidas que permitem o diagnóstico precoce de infeções virais dependem da deteção de ácidos nucleicos. Devido ao seu cariz técnico e custo elevado, estas técnicas não estão frequentemente disponíveis nos países em desenvolvimento, atrasando os resultados em áreas onde o equipamento de amplificação não está disponível. Métodos e plataformas de deteção alternativos estão continuamente a ser investigados, permitindo formas de deteção mais específicas, rápidas e baratas. Neste artigo foram discutidos os principais avanços feitos nos últimos oito anos usando MOFs como biossensores de vírus.

A maioria dos estudos relatados para deteção de vírus com MOFs usaram materiais com superfícies carregadas positivamente que interagem de forma expedita com as sondas de DNA (carregadas negativamente). As plataformas aqui descritas apresentam excelentes desempenhos, com alta especificidade em relação ao analito-alvo e limites de deteção muito baixos, tipicamente na ordem dos picomolar. 0 tempo de resposta em alguns casos foi de 2-3 minutos até 2 horas, sendo que este parâmetro justifica ainda alguma otimização para permitir respostas mais rápidas. Infelizmente, pouca ou nenhuma informação foi encontrada correlacionando o tamanho de cristal ou a porosidade dos MOFs com a eficácia da deteção de ácidos nucleicos virais. Será de esperar alguma dependência destas propriedades quando os cristais dos MOFs testados ou o tamanho de poro estiverem na escala nanométrica, que provavelmente terá influência nos tempos de deteção. A porosidade pode até ser um fator dificultador porque alguns exemplos mostraram que a recuperação da fluorescência e os tempos de recuperação tendem a ser maiores quando o poro não é suficientemente grande para a migração da cadeia de DNA. A relação entre dimensionalidade e capacidade de deteção é mais relevante, sendo que em alguns exemplos de estruturas em camadas, particularmente aquelas que são mais finas, foram as que apresentaram melhores resultados na interação com as sondas, baixando os limites de deteção.

Muito ainda pode ser feito nesta área de pesquisa para que os sensores baseados em MOFs, ou qualquer outro sensor desenvolvido para aplicações in situ, possam ser efetivamente colocados no mercado. Com a pandemia da COVID-19 certamente que o mundo não voltará a ser o mesmo e, inegavelmente, esta crise de saúde pública mundial irá incentivar avanços tecnológicos nos próximos anos.

\section{Agradecimentos}

Este trabalho foi desenvolvido no âmbito do projeto CICECO - Instituto de Materiais de Aveiro UIDB/50011/2020 \& UIDP/50011/2020, financiado por fundos nacionais através da Fundação para a Ciência e a Tecnologia/MCTES. O contrato de investigação de FF (REF-168-89-ARH/2018) é financiado por fundos nacionais (OE), através da FCT, no âmbito do contrato-quadro previsto nos $N .{ }^{\circ} 4,5$ e 6 do artigo 23 . do $^{\circ}$ Decreto-Lei 57/2016, de 29 de agosto, alterado pela Lei 57/2017, de 19 de julho. Gostaríamos de expressar o nosso agradecimento à Dr. ${ }^{a}$ Maria C. Gomes pelas interessantes discussões sobre biologia e pelo auxílio prestado na imagem criada usando a plataforma BioRender (biorender.com).

\section{Referências}

[1] J. E. Johnson, W. Chiu, Curr. Opin. Struct. Biol. 2000, 10, 229-235. DOl 10.1016/S0959-440X(00)00073-7.

[2] M. S. Draz, H. Shafiee, Theranostics 2018, 8, 1985-2017. DOI: 10.7150/ thno.23856.

[3] J. D. Perlmutter, M. F. Hagan, Annu. Rev. Phys. Chem. 2015, 66, 217-239. D0I: 10.1146/annurev-physchem-040214-121637.

[4] R. Sanjuán, P. Domingo-Calap, Cell. Mol. Life Sci. 2016, 73, 4433-4448. DOI 10.1007/s00018-016-2299-6.

[5] M. Laue, Chapter 1 - Electron Microscopy of Viruses, in T. Müller-Reichert (Ed.), Methods Cell Biol., Academic Press 2010, pp. 1-20. D0I: 10.1016/ s0091-679x(10)96001-9. 
[6] A. Mokhtarzadeh, R. Eivazzadeh-Keihan, P. Pashazadeh, M. Hejazi, N. Gharaatifar, M. Hasanzadeh, B. Baradaran, M. de la Guardia, TrAC, Trends Anal. Chem. 2017, 97, 445-457. DOI: 10.1016/j.trac.2017.10.005.

[7] ECDC, ecdc.europa.eu/en/geographical-distribution-2019-ncov-cases (acedido em 19/02/2021).

[8] R. S. Dhillon, D. Srikrishna, R. F. Garry, G. Chowell, Lancet Infect. Dis. 2015 15, 147-148. DOI: 10.1016/S1473-3099(14)71035-7.

[9] H. Chen, K. Liu, Z. Li, P. Wang, Clin. Chim. Acta 2019, 493, 138-147. DOl: 10.1016/j.cca.2019.03.008

[10] S. Sharma, J. Zapatero-Rodríguez, P. Estrela, R. O'Kennedy, Biosensors 2015 5. 577-601. DOl: 10.3390/bios5030577.

[11] M. Zarei, TrAC, Trends Anal. Chem. 2017, 91, 26-41. DOI: 10.1016/j. trac.2017.04.001.

[12] C. Chen, J. Wang, Analyst 2020, 145, 1605-1628. DOI: 10.1039/ C9AN01998G.

[13] S. M. Yoo, S. Y. Lee, Trends Biotechnol. 2016, 34, 7-25. DOI: 10.1016/j. tibtech.2015.09.012

[14] Y. Shen, T. -T. Tran, S. Modha, H. Tsutsui, A. Mulchandani, Biosens. Bioelectron. 2019, 130, 367-373. DOI: 10.1016/j.bios.2018.09.041

[15] W. Zhao, Y. Xing, Y. Lin, Y. Gao, M. Wu, J. Xu, Sens. Actuators Rep. 2020, 2 100004. DOI: 10.1016/j.snr.2020.100004

[16] H. Jin, R. Gui, J. Yu, W. Lv, Z. Wang, Biosens. Bioelectron. 2017, 91, 523-537. DOI: 10.1016/j.bios.2017.01.011.

[17] A. Kaushik, S. Tiwari, R. D. Jayant, A. Vashist, R. Nikkhah-Moshaie, N. El-Hage, M. Nair, Trends Biotechnol. 2017, 35, 308-317. DOI: 10.1016/j. tibtech.2016.10.001.

[18] M. Pohanka, Materials 2018, 11, 448. DOI: 10.3390/ma11030448.

[19] P. Skládal, TrAC, Trends Anal. Chem. 2016, 79, 127-133. DOI: 10.1016/j. trac.2015.12.009.

[20] J. Lei, H. Ju, Chem. Soc. Rev. 2012, 41, 2122-2134. DOI: 10.1039/C1CS15274B.

[21] M. Holzinger, A. Le Goff, S. Cosnier, Front. Chem. 2014, 2, 63. DOI: 10.3389/ fchem.2014.00063.

[22] D. Quesada-González, A. Merkoçi, Chem. Soc. Rev. 2018, 47, 4697-4709. DOI: 10.1039/C7CS00837F

[23] Q. Zhang, C. -F. Wang, Y. -K. Lv, Analyst 2018, 143, 4221-4229. DOI: 10.1039/C8AN00816G

[24] L. Jiao, J. Y. R. Seow, W. S. Skinner, Z. U. Wang, H. -L. Jiang, Mater. Today 2019, 27, 43-68. DOl: 10.1016/j.mattod.2018.10.038.

[25] H. -S. Wang, Coord. Chem. Rev. 2017, 349, 139-155. DOI: 10.1016/j. ccr.2017.08.015

[26] J. Zhou, G. Tian, L. Zeng, X. Song, X. -W. Bian, Adv. Healthcare Mater. 2018, 7, 1800022. DOl: 10.1002/adhm.201800022.

[27] J. S. Barbosa, F. Figueira, S. S. Braga, F. A. Almeida Paz, Chapter 4 - Metalorganic frameworks for biomedical applications: The case of functional ligands, in M. Mozafari (Ed.), Metal-Organic Frameworks for Biomedical Applications, Woodhead Publishing, 2020, pp. 69-92.

[28] J. Zhuang, A. P. Young, C. -K. Tsung, Small 2017, 13, 1700880. DOI: 10.1002/ smll.201700880.

[29] H. An, M. Li, J. Gao, Z. Zhang, S. Ma, Y. Chen, Coord. Chem. Rev. 2019, 384 , 90-106. DOl: 10.1016/j.ccr.2019.01.001.

[30] C. Wang, H. Sun, J. Luan, Q. Jiang, S. Tadepalli, J. J. Morrissey, E. D. Kharasch, S. Singamaneni, Chem. Mater. 2018, 30, 1291-1300. D0I: 10.1021/acs. chemmater.7b04713.

[31] Q. Xing, Y. Pan, Y. Hu, L. Wang, Front. Chem. 2020, 8, 642. DOI: 10.3389/ fchem.2020.00642.

[32] S. E. Miller, M. H. Teplensky, P. Z. Moghadam, D. Fairen-Jimenez, Interface Focus 2016, 6, 20160027. DOI: 10.1098/rsfs.2016.0027.

[33] D. Kukkar, K. Vellingiri, K. -H. Kim, A. Deep, Sens. Actuators, B 2018, 273, 1346-1370. DOI: 10.1016/j.snb.2018.06.128.

\section{*Filipe A. Almeida Paz}

Departamento de Química, Universidade de Aveiro.

CICECO - Instituto de Materiais de Aveiro.

Filipe Paz licenciou-se pela Universidade de Aveiro (UA, 2000) e doutorou-se pela Universidade de Cambridge (Peterhouse College, Reino Unido) em Metal-Organic Frameworks (MOFs) e materiais zeolíticos. Regressou a Portugal em 2004 para criar o seu grupo de investigação em MOFs e na
[34] C. Tamames-Tabar, D. Cunha, E. Imbuluzqueta, F. Ragon, C. Serre, M .J. Blanco-Prieto, P. Horcajada, J. Mater. Chem. B 2014, 2, 262-271. DOI: 10.1039/C3TB20832J.

[35] X. Liao, H. Fu, T. Yan, J. Lei, Biosens. Bioelectron. 2019, 146, 111743. DOI: 10.1016/j.bios.2019.111743.

[36] J. Yang, Y. -W. Yang, Small 2020, 16, 1906846. DOI: 10.1002/ smll.201906846

[37] S. Rojas, A. Arenas-Vivo, P. Horcajada, Coord. Chem. Rev. 2019, 388, 202226. DOI: 10.1016/j.ccr.2019.02.032.

[38] J. Dong, D. Zhao, Y. Lu, W. -Y. Sun, J. Mater. Chem. A 2019, 7, 22744-22767. DOI: 10.1039/C9TA07022B

[39] F. A. Paz, J. Rocha, Química 2014, 134, 11-21. DOI: 10.52590/M3.P666. A30001908.

[40] N. Stock, S. Biswas, Chem. Rev. 2012, 112, 933-969. DOI: 10.1021/ cr200304e.

[41] N. A. Khan, S. H. Jhung, Coord. Chem. Rev. 2015, 285, 11-23. DOI: 10.1016/j. ccr.2014.10.008.

[42] J. Klinowski, F. A. Almeida Paz, P. Silva, J. Rocha, Dalton Trans. 2011, 40, 321330. DOI: 10.1039/CODT00708K.

[43] L. Qin, L. -X. Lin, Z. -P. Fang, S. -P. Yang, G. -H. Qiu, J. -X. Chen, W. -H. Chen, Chem. Commun. 2016, 52, 132-135. DOI: 10.1039/C5CC06697B.

[44] S. - P. Yang, W. Zhao, P. -P. Hu, K. -Y. Wu, Z. - H. Jiang, L. -P. Bai, M. -M Li, J. -X. Chen, Inorg. Chem. 2017, 56, 14880-14887. DOI: 10.1021/acs. inorgchem.7b02107.

[45] G. - H. Qiu, Z. -H. Weng, P. -P. Hu, W. -J. Duan, B. -P. Xie, B. Sun, X. -Y. Tang, J. -X. Chen, Talanta 2018, 180, 396-402. DOI: 10.1016/j.talanta.2017.12.045.

[46] S. - P. Yang, S. - R. Chen, S. -W. Liu, X. -Y. Tang, L. Qin, G. -H. Qiu, J. -X. Chen, W. -H. Chen, Anal. Biochem. 2015, 87, 12206-12214. DOl: 10.1021/acs. analchem.5b03084.

[47] L. Chen, H. Zheng, X. Zhu, Z. Lin, L. Guo, B. Qiu, G. Chen, Z. -N. Chen, Analyst 2013, 138, 3490-3493. DOI: 10.1039/C3AN00426K

[48] Y. Pan, S. Zhan, F. Xia, Anal. Biochem. 2018, 546, 5-9. DOI: 10.1016/j. ab.2018.01.017.

[49] H. -Q. Zhao, G. - H. Qiu, Z. Liang, M. -M. Li, B. Sun, L. Qin, S. -P. Yang, W. -H. Chen, J. -X. Chen, Anal. Chim. Acta 2016, 922, 55-63. DOI: 10.1016/j. aca.2016.03.054.

[50] B. Sun, H. -Q. Zhao, B. -P. Xie, L. -P. Bai, Z. -H. Jiang, J. -X. Chen, J. Inorg. Biochem. 2017, 176, 17-23. DOI: 10.1016/j.jinorgbio.2017.07.024.

[51] M. Zhao, Y. Wang, Q. Ma, Y. Huang, X. Zhang, J. Ping, Z. Zhang, Q. Lu, Y. Yu, H. Xu, Y. Zhao, H. Zhang, Adv. Mater. 2015, 27, 7372-7378. DOl: 10.1002/ adma.201503648.

[52] J. M. Fang, F. Leng, X. J. Zhao, X. L. Hu, Y. F. Li, Analyst 2014, 139, 801-806. DOI: $10.1039 /$ C3ANO1975F

[53] J. F. Guo, C. M. Li, X. L. Hu, C. Z. Huang, Y. F. Li, RSC Adv. 2014, 4, 9379-9382. DOI: 10.1039/C3RA47389A

[54] J. Tian, Q. Liu, J. Shi, J. Hu, A. M. Asiri, X. Sun, Y. He, Biosens. Bioelectron. 2015, 71, 1-6. D0l: 10.1016/j.bios.2015.04.009.

[55] B. -P. Xie, G. - H. Qiu, B. Sun, Z. -F. Yang, W. -H. Zhang, J. -X. Chen, Z. -H. Jiang, Inorg. Chem. Front. 2019, 6, 148-152. DOI: 10.1039/C8QI01031E.

[56] B. -P. Xie, G. -H. Qiu, P. -P. Hu, Z. Liang, Y. -M. Liang, B. Sun, L. -P. Bai, Z. - H. Jiang, J. -X. Chen, Sens. Actuators, B 2018, 254, 1133-1140. DOI: 10.1016/j. snb.2017.06.085.

[57] J. Yang, W. Feng, K. Liang, C. Chen, C. Cai, Talanta 2020, 212, 120744. DOI: 10.1016/j.talanta.2020.120744

[58] L. Luo, F. Zhang, C. Chen, C. Cai, Microchim. Acta 2020, 187, 140. DOI 10.1007/s00604-020-4122-1.

[59] X. Wei, L. Zheng, F. Luo, Z. Lin, L. Guo, B. Qiu, G. Chen, J. Mater. Chem. B 2013, 1, 1812-1817. DOI: 10.1039/C3TB00501A.

[60] F. Figueira, J. S. Barbosa, R. F. Mendes, S. S. Braga, F. A. Almeida Paz, Mater. Today 2021, 43, 84-98. DOI: 10.1016/j.mattod.2020.10.024.

*Flávio Figueira

Departamento de Química, Universidade de Aveiro.

CICECO - Instituto de Materiais de Aveiro.

Flávio Figueira licenciou-se na Universi-

dade de Lisboa onde durante sete meses estagiou em Lille (França) sob o programa ERASMUS. Mais tarde fez um mestrado na mesma Universidade onde trabalhou em compostos radiofarmacêuticos no ITN e mais tarde doutorou-se pela Universidade de Aveiro em química orgânica onde foi possível estudar a síntese de porfirinas expandidas e reconhecimento de aniões no Grupo do Professor Jonathan Sessler (University of Texas). É atualmente investigador na Universidade de Aveiro (Portugal), onde tem desenvolvido trabalho na preparação de novos materiais híbridos baseados em Redes Metalo-Orgânicas capazes atuar como sensores e biossensores.

ffigueira@ua.pt ORCID.org/0000-0002-3685-9736 